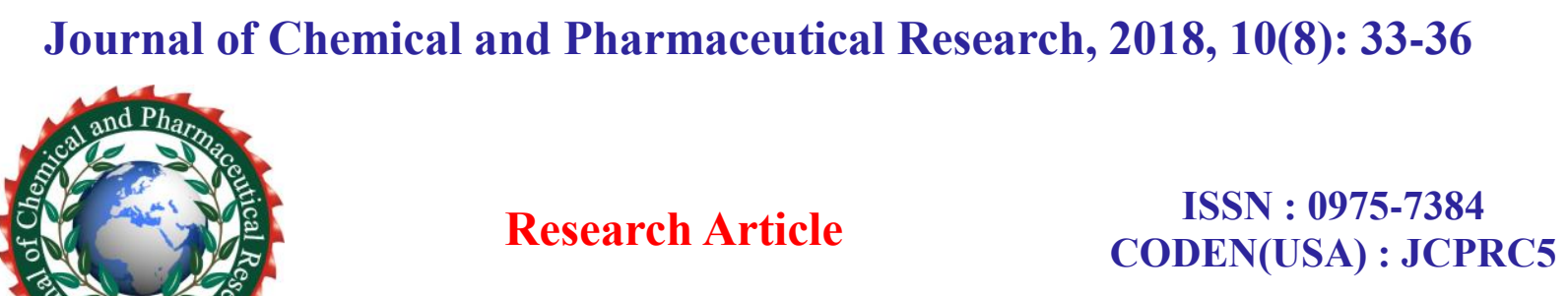

\title{
Anti-Microfilarial Activity of Rhizome Extract of Curcuma aerugenosa Roxb. (Zingiberaceae)
}

\author{
Nurlinda*, Idawati Payung, Putri Juana, and Adi Bejo Suwardi \\ Department of Biology Education, Universitas Samudra, Aceh Province, Indonesia
}

\begin{abstract}
This study aims to evaluate the anti micro filarial activity of the extract of C. aerugenosa rhizome (Zingiberaceae). Rhizomes of Curcuma aerugenosa were collected from the community garden in Langsa, Aceh, Indonesia. A total of $50 \mathrm{~g} \mathrm{C}$. aerugenosa flour were weighed and dissolved in $10 \mathrm{ml}$ of distilled water, stirred with a spatula until mixed, then filtered. A total of $2 \mathrm{ml}$ of Curcuma rhizome extract given to Rabbit with different concentration i.e. 5\%, 10\%, 15\%, 20\%, 25\% and observed every 24 hours. The highest percentage of microfilaria decrease after 24 hours was found in P6 (27.54\%) followed by P4 (22.22\%), P5 (20,24\%), P3 (18,67\%), P2 (17,28) \%) and P1 (12.82\%). The percentage of microfilarial reduction by an extract of $C$. aerugenosa rhizome was $49.28 \%$ after 72 hours of treatment. Statistical analysis showed that there was a significant effect of all treatment on the decrease of microfilariae amount $(P<0,05)$. Extract of $C$. aerugenosa rhizome has an anti-microfilarial effect with the best concentration found at $25 \%$ concentration.
\end{abstract}

Keywords: Curcuma aerugenosa; Filariasis; Rabbit; Microfilariae; Rhizome

\section{INTRODUCTION}

Filariasis or we known as lymphatic filariasis is the major forms of human filarial nematode infections that may lead to severe pathology caused by Wuchereria bancrofti and Brugia spp., and onchocerciasis. Brugia malayi and Brugia timori is found to be the cause of lymphatic filariasis in Southeast Asia. The parasite life cycles include a sexually dimorphic adult stage that occurs in the lymphatic system of the human host. After maturation, the adults produce thousands of first-stage larvae (microfilariae). Microfilariae are present in the in the peripheral blood during the night [1]. Indonesia is one of the regions with high lymphatic filariasis cases. A total of 13.032 filariasis cases were found in Indonesia by 2015. Aceh province became one of the areas with high filariasis cases (2.372 cases) [2]. The number of cases can continue to grow because not all patients with lymphatic filariasis are recorded. Lymphatic filariasis can present as recurrent debilitating fevers, lymphangitis, hydrocoele and lymphoedema [3].At an advanced stage, this disease can cause permanent disability in the form of the leg, arm and breast enlargement [4]. Lack of vaccine and the absence of more effective drugs for vector control caused increasing for transmission of lymphatic filariasis [5].

Curcuma aerugenosa is one of the plants which potential for use as filariasis medicine. C. aerugenosa is a perennial plant having a short stem with large oblong leaves. Rhizome is large and aromatic. Sessil tubers are branched and many roots in the tuber. Leafly shoot is $45-60 \mathrm{~cm}$ high. The petiole is a long as lamina, oblonglanceolate, a purplish patch along either side of the midrib on the upper side. The rhizome of C. aerugenosa contains bioactive compounds such as saponins, flavonoids, polyphenols, triterpenoids, and glucans [6]. The black rhizome is used for excavation and anti-rheumatism or inflammation, skin diseases [7] cough and asthma, anti-microbial,anti-fungal antioxidants [8] and antihelminthics [9]. This study aims to evaluate the anti micro filarial activity of the extract of $C$. aerugenosa rhizome (Zingiberaceae). 


\section{EXPERIMENTAL SECTION}

\section{Plant Materials}

Rhizomes of Curcuma aerugenosa were collected from the community garden in Langsa, Aceh, Indonesia.

\section{Preparation of Extract}

The collected plant material (Rhizomes) of Curcuma aerugenosa were washed thoroughly in water, cut into small pieces and dried oven at $800 \mathrm{C}$ for 30 minutes. The material is mashed using a blender so that the resulting Curcuma flour. A total of $50 \mathrm{~g} \mathrm{C}$. aerugenosa flour were weighed and dissolved in $10 \mathrm{ml}$ of distilled water, stirred with a spatula until mixed, then filtered.

\section{Test Organism}

A total of 18 of Rabbit (Lepus nigricollis) each weighing between 300-400 g was bought from the breeder in Langsa, Aceh. Rabbits kept for two weeks in a cage with size $60 \times 90 \times 50 \mathrm{~cm}$.

\section{Anthelmintic Activity}

All the extracts and drug solution were fleshy prepared before starting the experiment. Six group with three rabbits in each were placed in cage experiment. A total of $1 \mathrm{ml}$ of human blood taken from filariasis patients (blood has been observed in the laboratory) injected into the rabbit. After 7 days, $1 \mathrm{ml}$ of rabbit blood was taken and observed under a microscope to confirm the presence of microfilariae. A total of $2 \mathrm{ml}$ of Curcuma rhizome extract given to Rabbit with different concentration following the formula.

P1: Control

P2: 5\% rhizome extract of Curcuma aerugenosa

P3: $10 \%$ rhizome extract of Curcuma aerugenosa

P4: $15 \%$ rhizome extract of Curcuma aerugenosa

P5: 20\% rhizome extract of Curcuma aerugenosa

P6: $25 \%$ rhizome extract of Curcuma aerugenosa.

The blood of the rabbit was checked after 24 hours, 48 hours, and 72 hours. The number of observed microfilariae is calculated and recorded.

\section{Statistical Analysis}

Data were subjected to statistical analysis using ANOVA to compare the mean percentage of reduction in microfilariae with respective control.

\section{RESULT AND DISCUSSION}

The results showed that the percentage reduction in the number of microfilariae increased along with the increase of the extract of $C$. aerugenosa rhizome concentration (Table 1).

Table 1: Percentage reduction microfilarial by an extract of $C$. aerugenosa rhizome

\begin{tabular}{|c|c|c|c|}
\hline \multirow{2}{*}{ Treatment } & \multicolumn{3}{|c|}{$\begin{array}{c}|c| \\
\text { (\%) }\end{array}$} \\
\cline { 2 - 4 } & After 24 hours & After 48 hour & After 72 hour \\
\hline P1 & $12.82 \pm 3.39$ & $17.95 \pm 5.58$ & $23.08 \pm 4.44$ \\
\hline P2 & $17.28 \pm 3.26$ & $22.22 \pm 5.65$ & $25.93 \pm 7.71$ \\
\hline P3 & $18.67 \pm 3.52$ & $26.67 \pm 3.52$ & $36.00 \pm 4.61$ \\
\hline P4 & $22.22 \pm 3.67$ & $27.78 \pm 3.67$ & $40.28 \pm 6.05$ \\
\hline P5 & $20.24 \pm 3.14$ & $27.38 \pm 314$ & $41.67 \pm 5.19$ \\
\hline P6 & $27.54 \pm 3.83$ & $37.68 \pm 2.09$ & $49.28 \pm 6.31$ \\
\hline
\end{tabular}

P1: Control; P2: 5\% extract of C. aerugenosa rhizome; P3: $10 \%$ extract of $C$. aerugenosa rhizome; P4: $15 \%$ extract of C.aerugenosa rhizome; P5: 20\% extract of $C$. aerugenosa rhizome; P6: $25 \%$ extract of $C$. aerugenosa rhizome

The highest percentage of microfilaria decrease after 24 hours was found in P6 (27.54\%) followed by P4 (22.22\%), P5 (20,24\%), P3 (18,67\%), P2 (17,28) \%) and P1 (12.82\%). In the measurements after 48 hours and 72 hours, the highest percentage reduction in microfilariae was also raised on P6 with a percentage of $37.68 \%$ and $49.28 \%$ respectively. Statistical analysis showed that there was a significant effect of all treatment on the decrease of microfilariae amount $(\mathrm{P}<0,05)$. The percentage of decrease of microfilariae amount by extract of extract of $C$. aerugenosa rhizome was higher compared with Vitex negundo leaf extract $(15,23 \%)$ and Ricinus 
communis leaf extract (22,23\%) [10] and Butea monosperma leaf extract (11.75\%) [11] after 24 hours of treatment. Nevertheless, the percentage decrease in the number of microfilariae by an extract of $C$. aerugenosa rhizome was lower compared to Cordyline fruticosa leaf extract $(87.50 \%)$ [12].

The decline in the number of microfilariae in rabbit blood is thought to be caused by the chemical content contained in the extract of $C$. aerugenosa rhizome. The rhizome of $C$. aerugenosa is known to contain various bioactive compounds, such as saponins, flavonoids, polyphenols, triterpenoids, tannins, and glucan. Saponins, flavonoids, and tannins are known to have anthelmintic effects [13,14].

Saponin has an anthelmintic effect by lowering the surface tension of the worm membrane wall and inhibiting the action of cholinesterase enzymes and proteinases so that the microfilariae worms will experience muscle paralysis and eventually die [15]. Saponins also cause irritation of the mucous membranes of the gastrointestinal tract, suppress the nervous system, respiratory system and motion system [16,17]. When saponins are swallowed by microfilaria worms it is thought to cause irritation to the mucous membrane, thus interfering with the absorption of nutrients in the intestinal worms. Depression of the nervous system and the motion system causes a common weakness in the worms, whereas the depression of the respiratory system causes the lack of oxygen so that the worm dies.

Flavonoid compounds have pharmacological effects on blood vessels through the occurrence of capillary vasoconstriction and decrease the permeability of blood vessels [18].This causes the presence of blood vessel disorders so that the substances of food and oxygen needed for the survival of worms are disrupted and can accelerate the death of the worms [19]. Flavonoids that come into contact with the body of the worm, will quickly absorb and cause denaturation of proteins in the network of worms causing the death of the worms.

Tanin is also known to have an anthelmintic effect. The results of Nalue et al [20] showed that the ethanol extract of Zanthoxylum chalybeum root containing tannin compound has anthelmintic power in vitro. Tannin compounds cause nutritional deficiencies caused by the binding of the enzymes that play a role in Tannins enter the digestive tract of microfilaria worms and will agglomerate the protein in the gastrointestinal wall causing metabolic disturbance and worm homeostasis [21].

\section{CONCLUSIONS}

Extract of $C$. aerugenosa rhizome has an anti-microfilarial effect with the best concentration found at $25 \%$ concentration. The percentage of microfilarial reduction by an extract of C. aerugenosa rhizome was $49.28 \%$ after 72 hours of treatment.

\section{ACKNOWLEDGEMENT}

This study was supported by the Ministry of Research, international journal of pharmacy and pharmaceutical sciences.

\section{REFERENCES}

[1] Hoerauf A. Clin Microbiol Infect. 2011, 17(7), 977-985.

[2] Ministry of Health of Indonesia. Jakarta, 2015.

[3] World Health Organization. Wkly Epidemiol. 2009, 85, 365-372.

[4] MOH RI. Jakarta. 2010-2014.

[5] Ottesen EA; Duke BOL; Daram M; Bahbehani K. World Health Organ. 1997, 75,491-503.

[6] Nalue AS; Mbaria JM; Kimenju JW. Afr J Pharm Pharmacol. 2013, 7(23), 605-1614.

[7] Djuanda Adhi. Jakarta. 2007.

[8] Nurcholis W; Khumaida N; Syukur M; Bintang M; Ardyani IDAAC. Int J Res Ayurveda Pharm. 2015. 6(5), 634-637.

[9] Babu SPS; Priya D; Ghosh NK; Saha A; Sukul NC; Bhattacharya S. J. Pharmacol. 2006.

[10] Hernandez JLF; Gonzales G; SAscencio VJ; Espitia JLF; Saavendra GF. Proc West Pharmaco Soc. 2005, 48, 77.

[11] Share KN. Int J Pharmtech Res. 2012. 4(3), 1181-1184.

[12] Asih Astir. Faculty of Technobiology University of Atma Jaya Yogyakarta. 2014.

[13] Nadia H. Faculty of Veterinary Medicine Bogor Agricultural University. 2008.

[14] Nalue AS; Mbaria JM; Kimenju JW. Afr J Pharm Pharmacol. 2013, 7(23), 605-1614.

[15] Singh KS; Nagaich. J Parasit Dis. 1999, 23, 113-116

[16] Gardner RJ. Veterinary Toxycology. Bailiere Tindall and Cox, London. 1999, 415.

[17] Nicholson JA. Bailliere Tindall.1947.

[18] Sulistia. Faculty of Medicine UI. Jakarta. 1987

[19] Vickery ML; B Vickery. Secondary plant metabolism. The Macmillan. 1981. 
[20] Budiyanti RT. Medical Jur Medis. 2010.

[21] Dewi FK. Department of Biology MIPA Sebelas Maret University. Surakarta.2010. 